1 Supporting Information for:

2

\title{
Source Contributions to Ambient Fine Particulate Matter for Canada
}

Jun Meng ${ }^{1 *}$, Randall V. Martin ${ }^{1,2,3}$, Chi Li $^{1}$, Aaron van Donkelaar ${ }^{1}$, Zitely A. Tzompa-Sosa ${ }^{4}$, Xu Yue ${ }^{5}$, Jun-Wei Xu ${ }^{1}$, Crystal L. Weagle ${ }^{1}$, Richard T. Burnett ${ }^{6}$

\section{Affiliations}

${ }_{1}^{1}$ Department of Physics and Atmospheric Science, Dalhousie University, Halifax, Nova Scotia, B3H 4R2, Canada

${ }^{2}$ Smithsonian Astrophysical Observatory, Harvard-Smithsonian Center for Astrophysics, Cambridge, MA 02138, USA

$12{ }^{3}$ Department of Energy, Environmental \& Chemical Engineering, Washington University in St. Louis, St. Louis,

13 Missouri, 63130, USA

$14{ }^{4}$ Department of Atmospheric Science, Colorado State University, Fort Collins, Colorado, 80523, USA

$15{ }^{5}$ School of Environmental Science and Engineering, Nanjing University of Information Science \& Technology,

16 Nanjing, 210044, China

$17{ }^{6}$ Health Canada, Ottawa, Ontario, K1A 0k9, Canada

*Correspondence to Jun Meng (Jun.Meng@Dal.ca) 


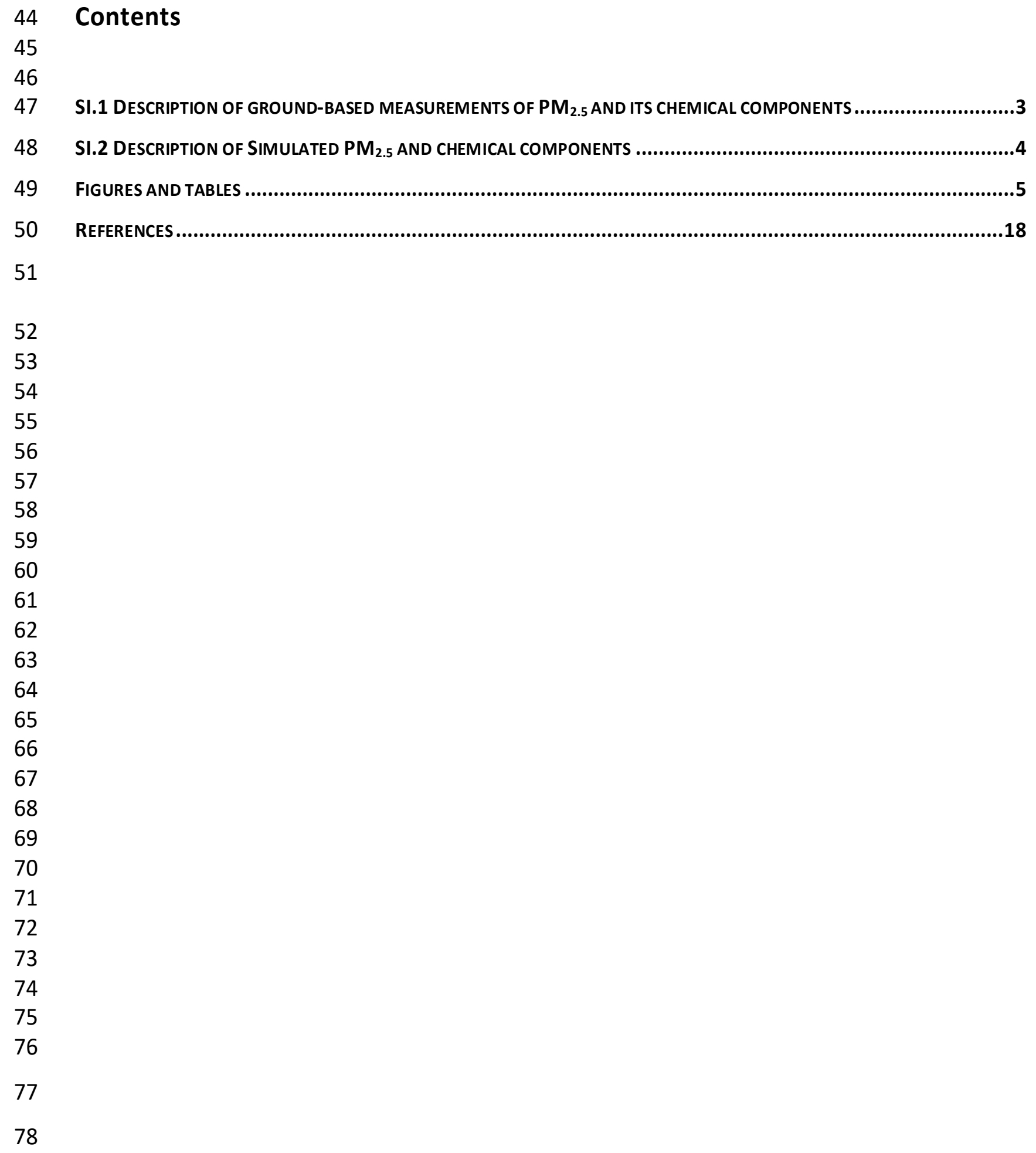

78 


\section{SI.1 Description of ground-based measurements of $\mathrm{PM}_{2.5}$ and its chemical components}

We collected ground-based measurements of $\mathrm{PM}_{2.5}$ concentrations and its chemical

81 components from several networks across North America in 2013. The $\mathrm{PM}_{2.5}$ mass

82 measurements included the Canadian National Air Pollution Surveillance Network (NAPS,

83 http://www.ec.gc.ca/rnspa-naps/ ), the U.S. Environmental Protection Agency (EPA) federal

84 reference method (EPA-FRM, http://www.epa.gov/outdoor-air-quality-data/) and the

85 Interagency Monitoring of Protected Visual Environments (IMPROVE,

86 http://views.cira.colostate.edu/fed/DataWizard/ ). The networks for ground-based

87 measurements of chemical composition included the EPA chemical speciation network (EPA-

88 CSN, http://www.epa.gov/ttn/airs/airaqs/ ), IMPROVE, NAPS and the Clean Air Status and

89 Trends Network (CASTNET, http://www.epa.gov/castnet/ ). The NAPS network provided 24-hr

90 average composition data every third day across Canada ${ }^{1}$.The IMPROVE network provided 24-

$91 \mathrm{hr}$ average composition data every third day over the national parks in the United States. The

92 EPA-CSN network located sites mainly in urban or suburban areas, with reported 24-hr average

93 composition data every three or six days. The CASTNET network provided weekly average

94 inorganic ion measurements. We calculated ammonium concentrations from sulfate and nitrate

95 measurements of the IMPROVE network by assuming the aerosol is in neutral state. We

96 calculated organic matter (OM) from measured organic carbon (OC) using a spatially and

97 seasonally varying OM/OC ratio². 


\section{SI.2 Description of Simulated $\mathrm{PM}_{2.5}$ and chemical components}

Both the measurements and the downscaled simulation exhibited enhanced $\mathrm{PM}_{2.5}$ concentrations across the eastern United States extending into southern Ontario. Regional

101 enhancements across northern Canada reflect wildfire influence as discussed further below. We

102 found a high degree of consistency of the downscaled simulation with in situ $\mathrm{PM}_{2.5}$

103 concentrations, with a root mean square error (RMSE) of $1.79 \mu \mathrm{g} \mathrm{m}^{-3}$ and correlation coefficient 104 (r) of 0.77 over North America (Figure S1).

105 The downscaled simulation was most consistent with measured chemical components 106 for sulfate $(r=0.76$, slope=0.88), ammonium $(r=0.74$, slope=1.12), nitrate $(r=0.69$, slope $=0.75)$ 107 and to a lesser extent OM $(r=0.68$, slope $=0.88)$. The enhanced concentrations of sulfate-nitrate108 ammonium aerosols south of the Great Lakes were reproduced by the simulation, albeit with a 109 slight underestimate of sulfate and nitrate. The measured enhancement of OM over the 110 southeastern U.S. was well represented in the simulation. The simulation exhibited hotspots of 111 black carbon (BC) concentration associated with major urban areas (Figure S2).

Figure S3 showed the fractional contribution of different chemical components to total

113 annual mean $\mathrm{PM}_{2.5}$ concentrations. OM accounts for more than $40 \%$ of the total $\mathrm{PM}_{2.5}$

114 concentrations over many regions in North America. Sulfate-nitrate-ammonium (SNA) were 115 major components of total $\mathrm{PM}_{2.5}$ over North America contributing 44\% of population-weighted $116 \mathrm{PM}_{2.5}$ over Canada and 51\% over the United States. Sulfate had a major influence on 117 population-weighted $\mathrm{PM}_{2.5}$, accounting for $22 \%$ over Canada and $25 \%$ over the United States.

118 Nitrate and ammonium contribute similarly over Canada and the United States, accounting for 119 roughly $12 \%$ of population-weighted $\mathrm{PM}_{2.5}$ mass respectively. $\mathrm{BC}$, dust and sea salt typically 
121 with the exception of mineral dust in the southwest.

\section{$123 \quad$ Figures and tables}

124 Table S1 Percentage contribution of diesel sector to the Canadian transport sector

\begin{tabular}{l|l|l|l|l|l}
\hline & Canada & $\begin{array}{l}\text { Atlantic } \\
\text { Canada }\end{array}$ & $\begin{array}{l}\text { Northern } \\
\text { Canada }\end{array}$ & $\begin{array}{l}\text { Western } \\
\text { Canada }\end{array}$ & $\begin{array}{l}\text { Central } \\
\text { Canada }\end{array}$ \\
\hline Percentage & $35 \%$ & $37 \%$ & $37 \%$ & $36 \%$ & $35 \%$ \\
\hline
\end{tabular}
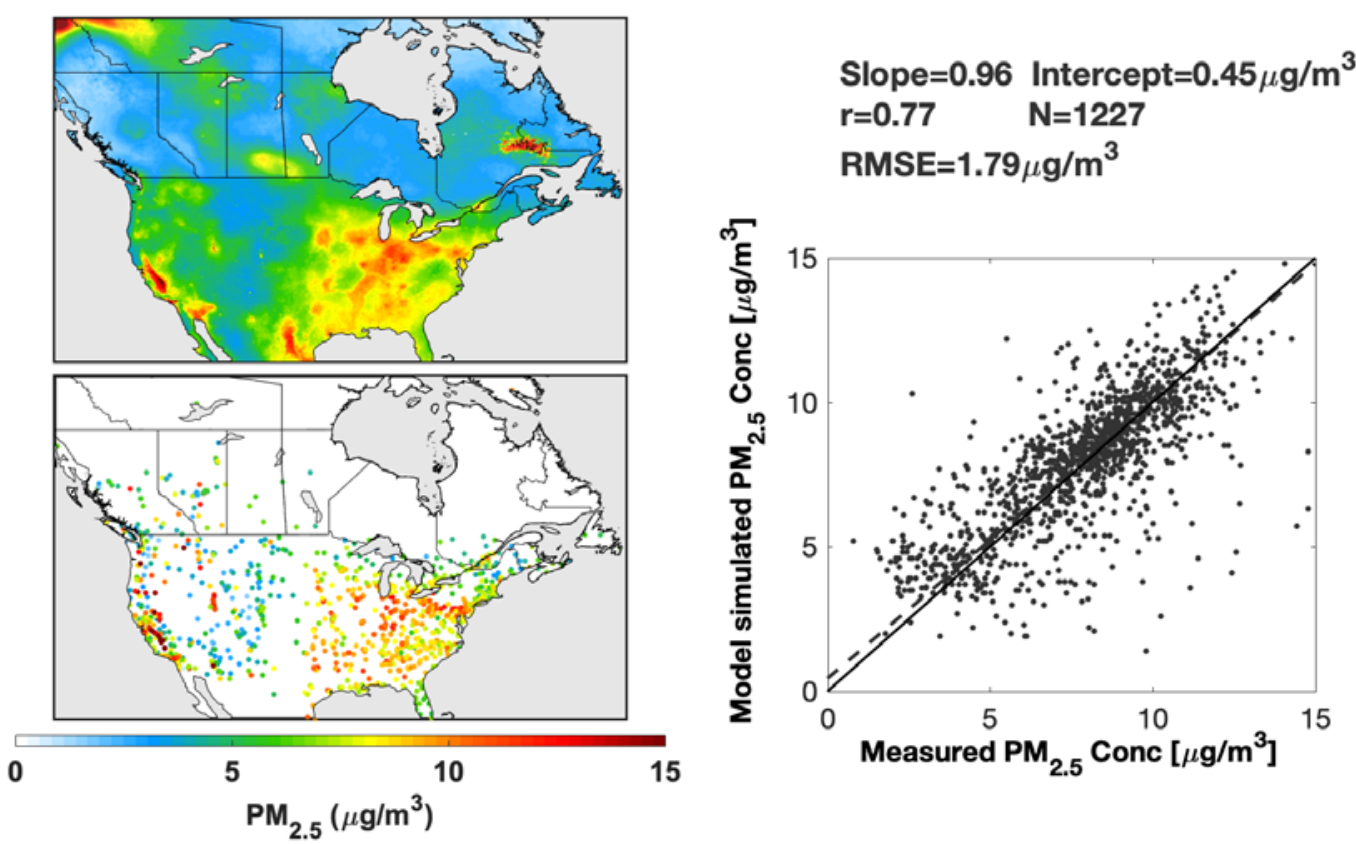

Figure S1. Annual mean PM2.5 concentrations for 2013. The top-left panel shows the baseline downscaled simulation. The bottom-left panel shows ground-based measurements. The right panel shows the corresponding scatter plot with root mean square error (RMSE), correlation coefficient( $r$ ) and slope 130 calculated with reduced major axis linear regression. $N$ is the number of valid ground-based monitoring records. The best fit line is dashed. The 1:1 line is solid. Figure was created using MATLAB_R2016b. 


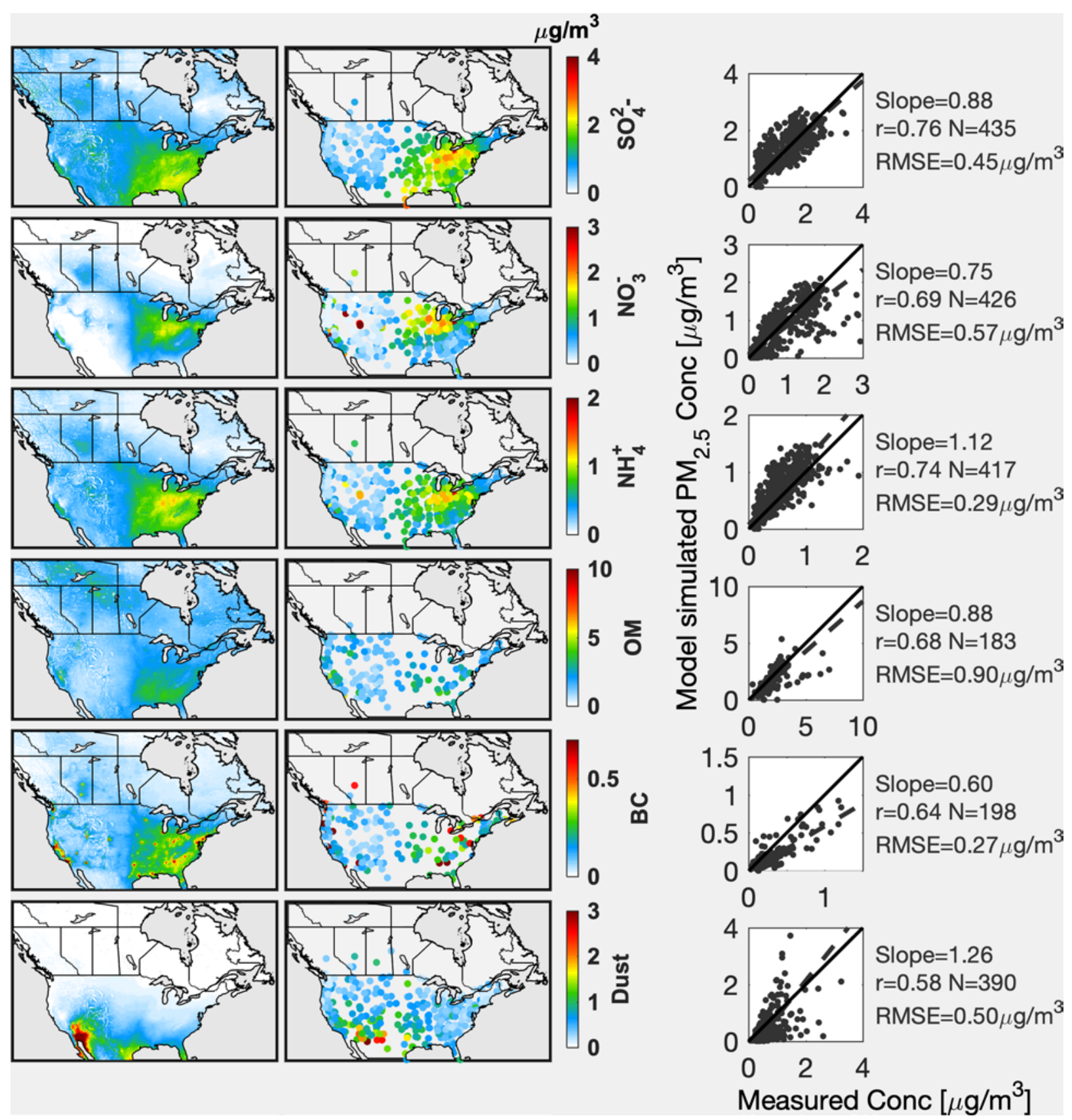

Figure S2. Annual mean chemical components in baseline downscaled simulation (left) and ground-based measurements (middle). The right column contains scatter plots between simulated and observed species concentrations using reduced major axis linear regression. Slope, root mean square error (RMSE) and correlation coefficient $(r)$ are reported. The best fit line is dashed. The 1:1 line is solid. Figure was 137 created using MATLAB_R2016b. 

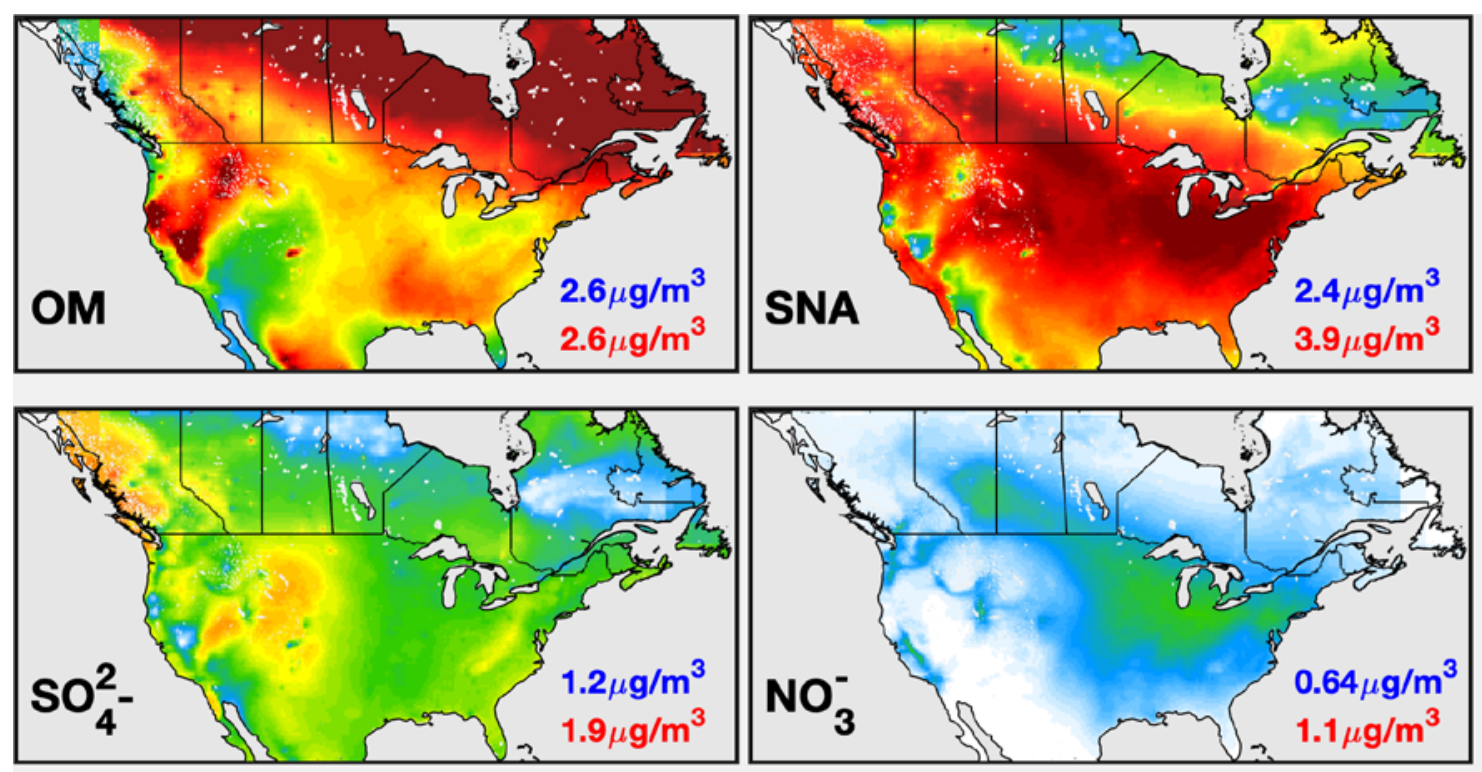

50
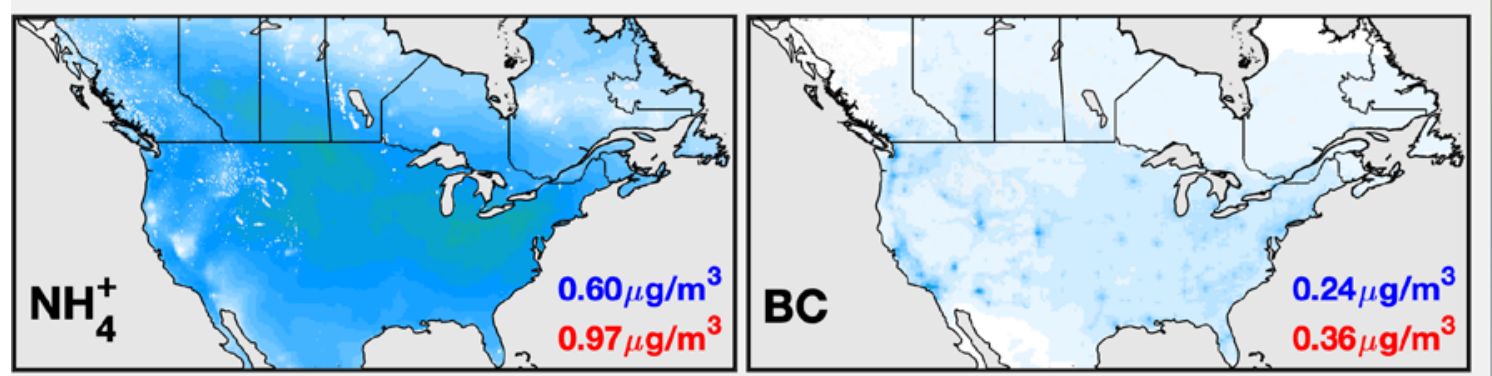

20

10
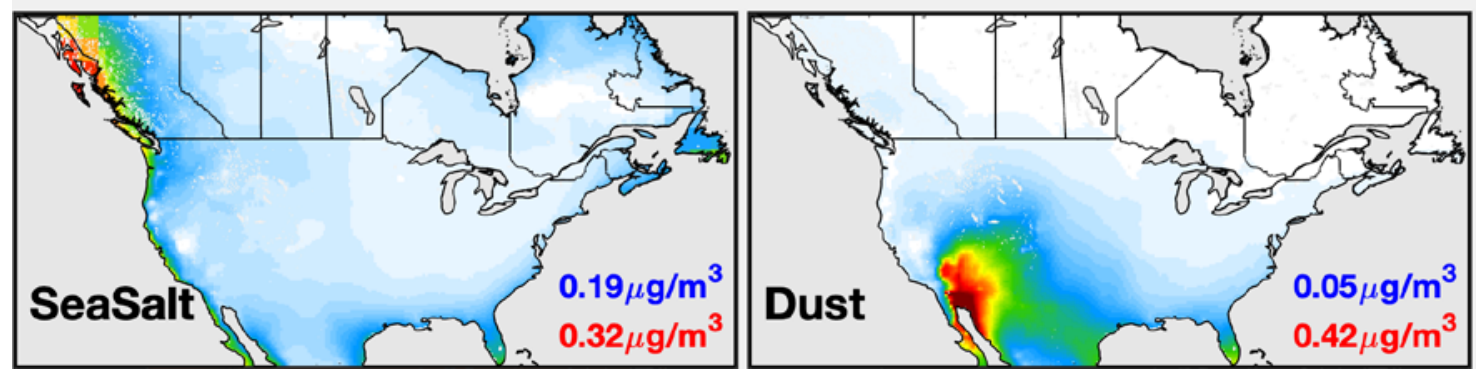

0

Figure S3. Fractional contribution of different chemical components to total annual mean $P M_{2.5}$ concentrations. Aerosol water is associated with each chemical component at 35\% RH. Abbreviations are sulfate-nitrate-ammonium (SNA), organic mass (OM) and black carbon (BC). Inset values are population-weighted annual mean PM2.5 concentrations resulting from each chemical component over the U.S. (red) and Canada (blue). Figure was created using MATLAB_R2016b. 

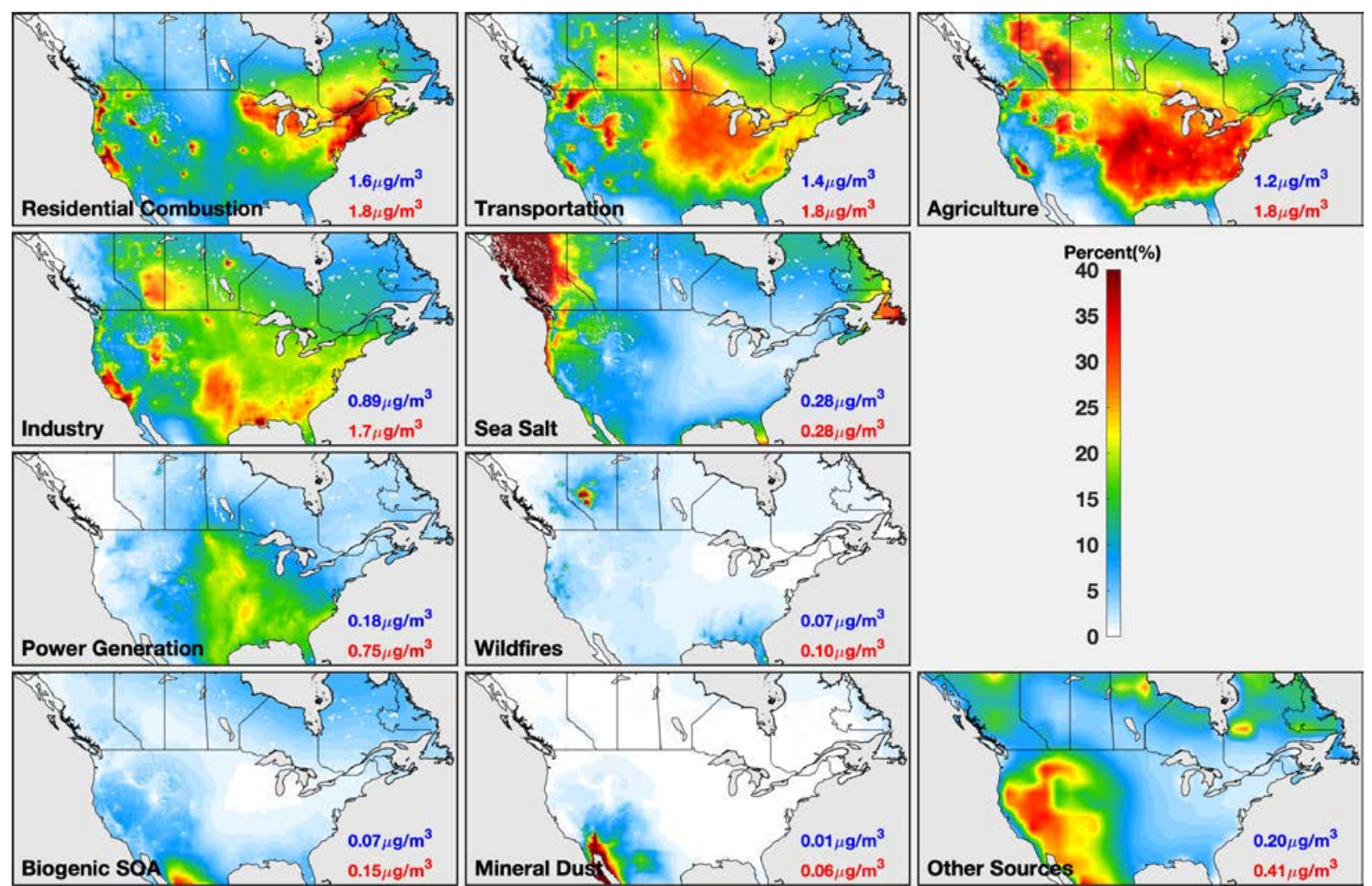

146 Figure S4. Contribution of individual emission sector to $P M_{2.5}$ concentrations in winter (December, 147 January, February). Other Sources includes volcano, dimethyl sulfide (DMS), and long-range transport 148 (LRT) from Asia, Europe and Alaska. Inset values are population-weighted annual mean PM 2.5 149 concentrations attributing to each sector over the U.S. (red) and Canada (blue). Figure was created 150 using MATLAB_R2016b. 

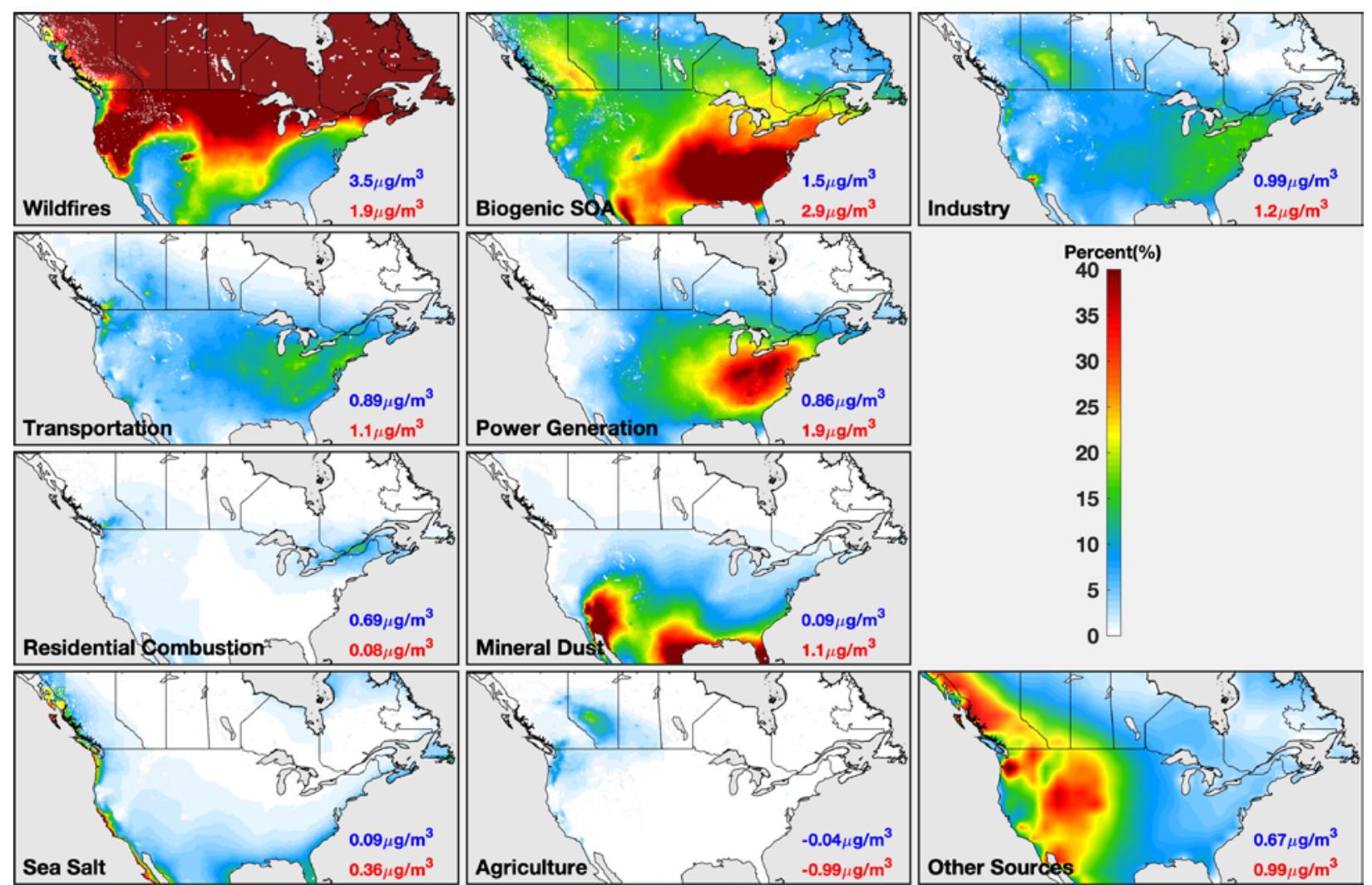

Figure S5. As in Figure S4 but in summer (June, July, August). Figure was created using 153 MATLAB_R2016b.

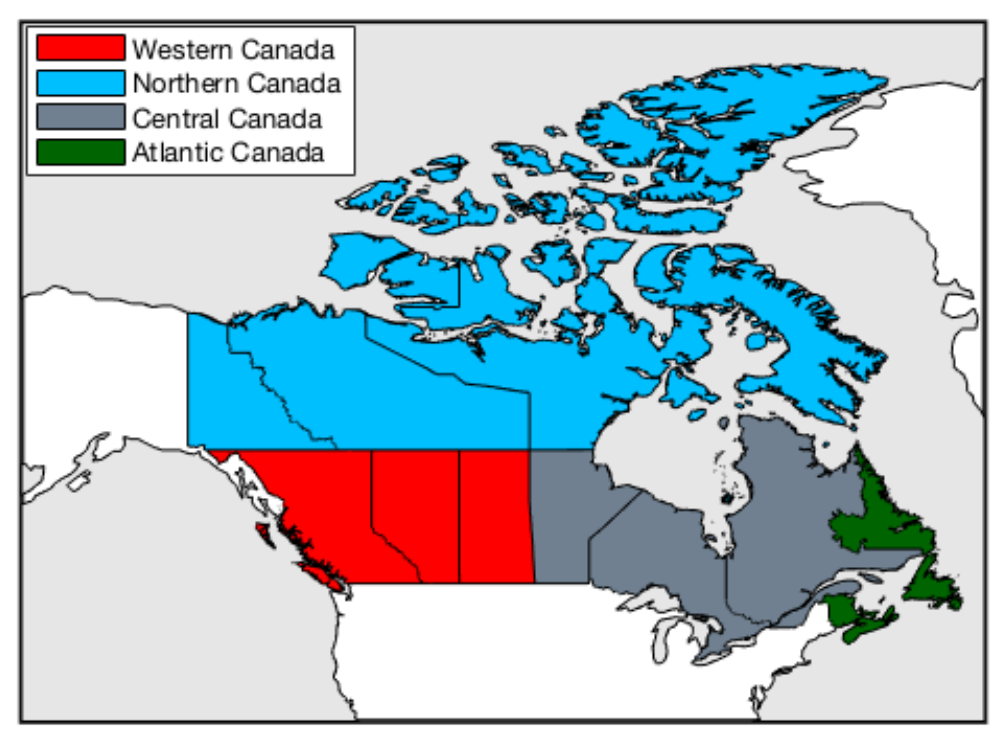

154

155 Figure S6. Domain of regions in Canada. Figure was created using MATLAB_R2016b. 


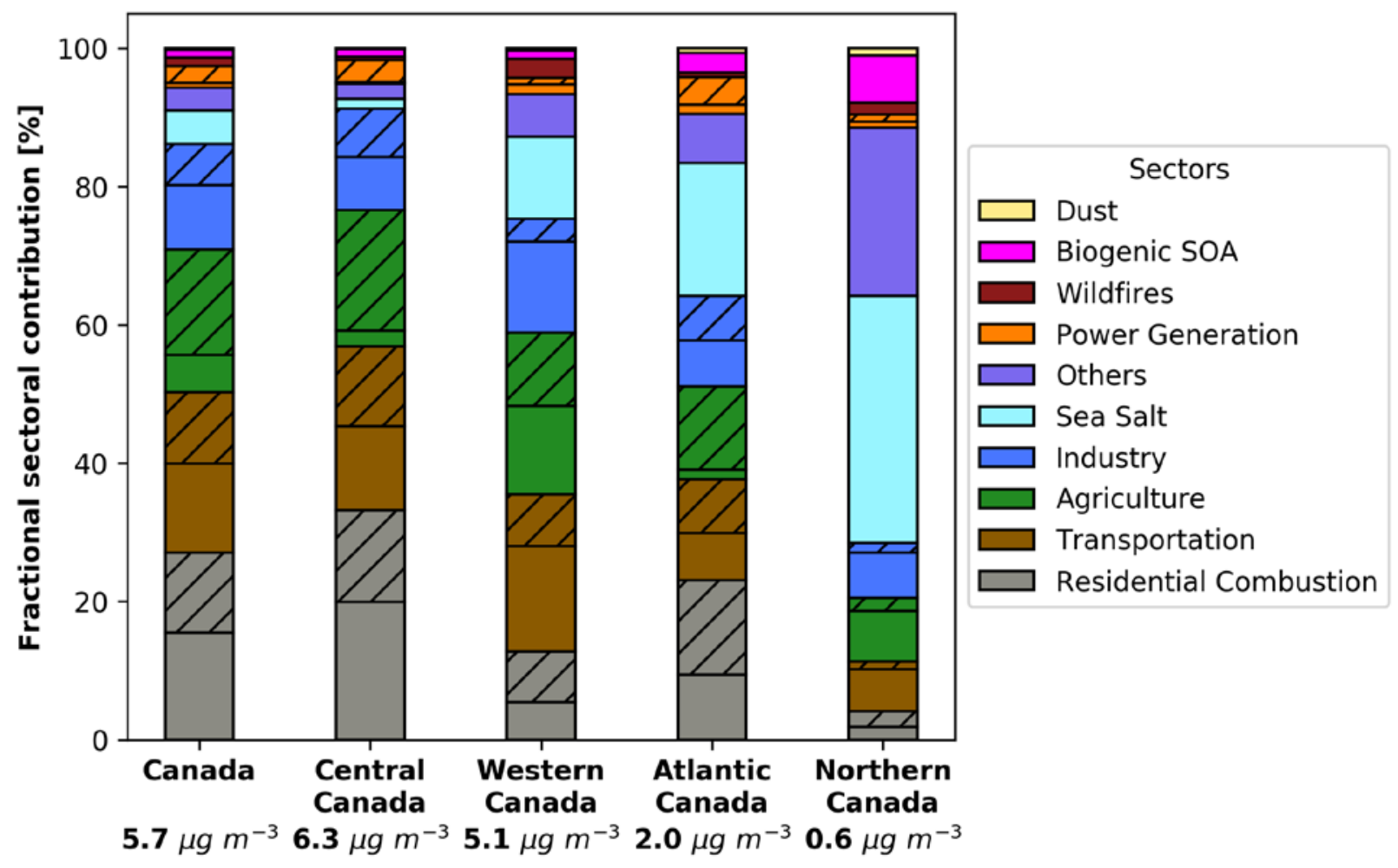

Figure S7. Fractional contribution of different sectors to population-weighted average PM 2.5

158 concentrations over different regions in Canada in winter (December, January, February). The number under each bar represents the total population-weighted annual mean PM 2.5 concentrations over that region. The hatched part in each sector represents the fractional contribution from the United States. Others include dimethyl sulfide (DMS), volcano, and long-range transport (LRT) from Asia, Europe and Alaska. 


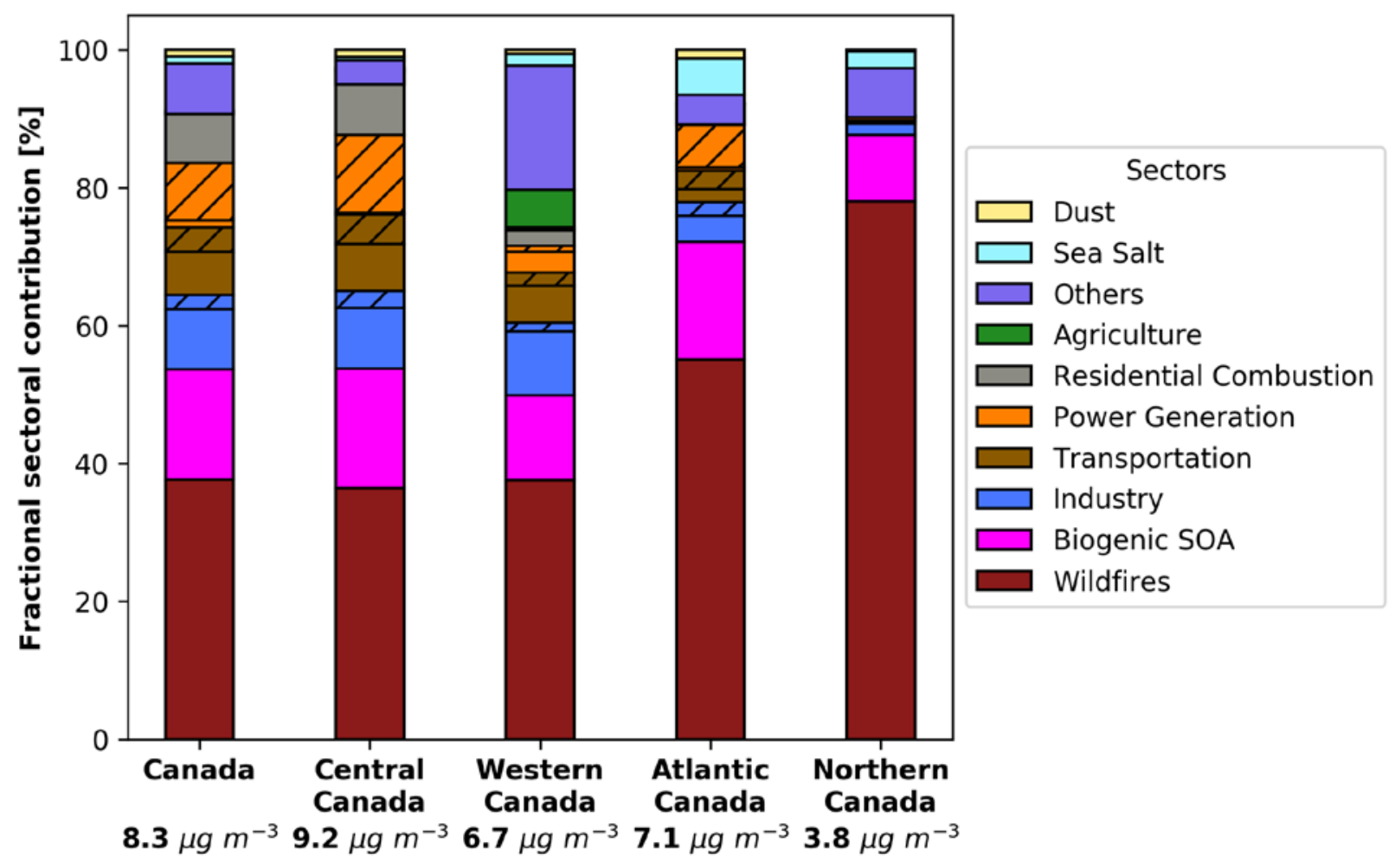

$8.3 \mu \mathrm{g} \mathrm{m}^{-3} 9.2 \mu \mathrm{g} \mathrm{m}^{-3} 6.7 \mu \mathrm{g} \mathrm{m}^{-3} 7.1 \mu \mathrm{g} \mathrm{m}^{-3} 3.8 \mu \mathrm{g} \mathrm{m}^{-3}$

164 Figure S8. As in Figure S7 but in summer (June, July, August). 


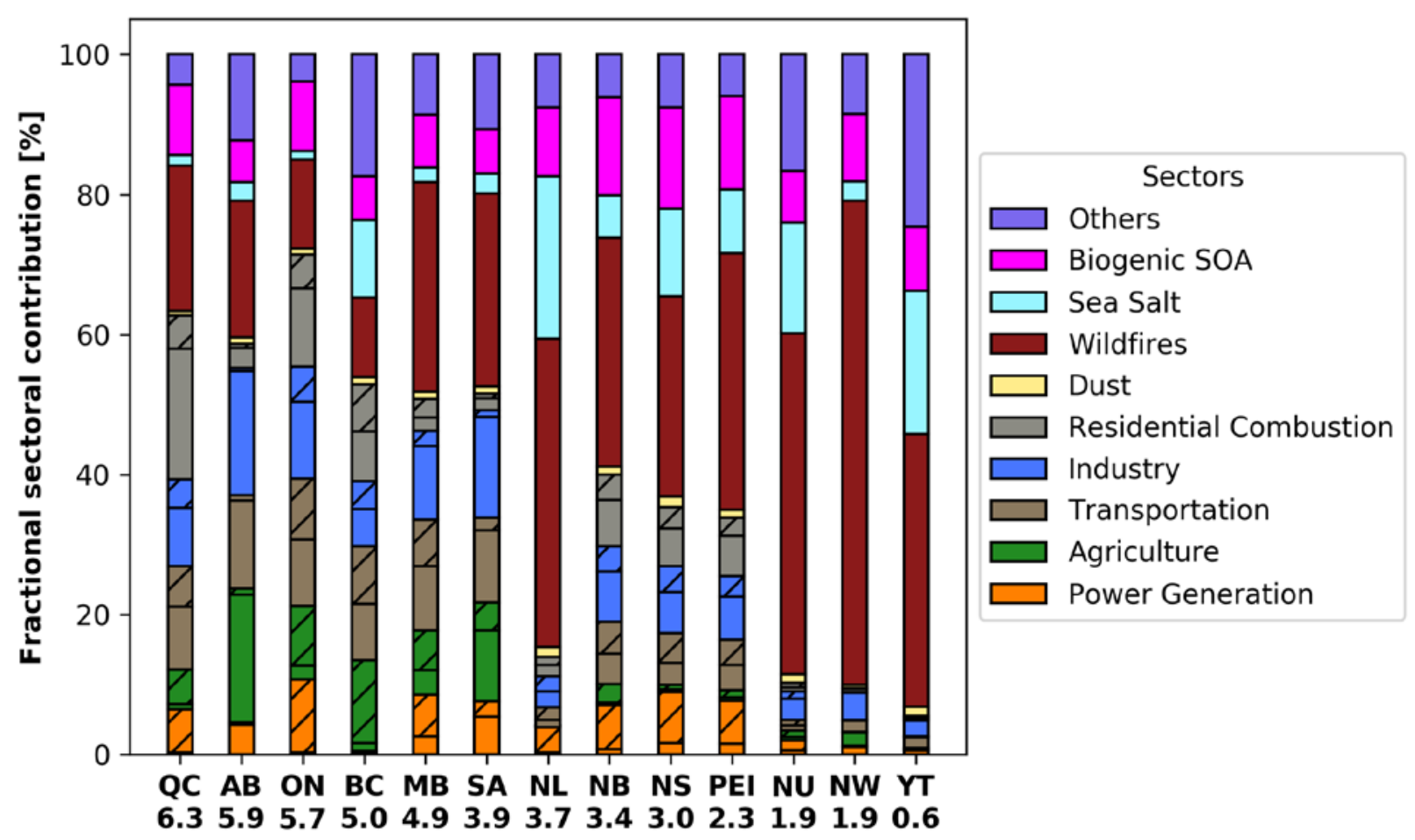

Figure S9. Fractional contribution of different sectors to population-weighted average PM2.5 concentrations over different provinces in Canada. The number under each bar represents the total population-weighted annual mean PM2.5 concentrations over that region. The hatched part in each sector represents the fractional contribution from the United States. Others include dimethyl sulfide (DMS), volcano, and long-range transport (LRT) from Asia, Europe and Alaska.

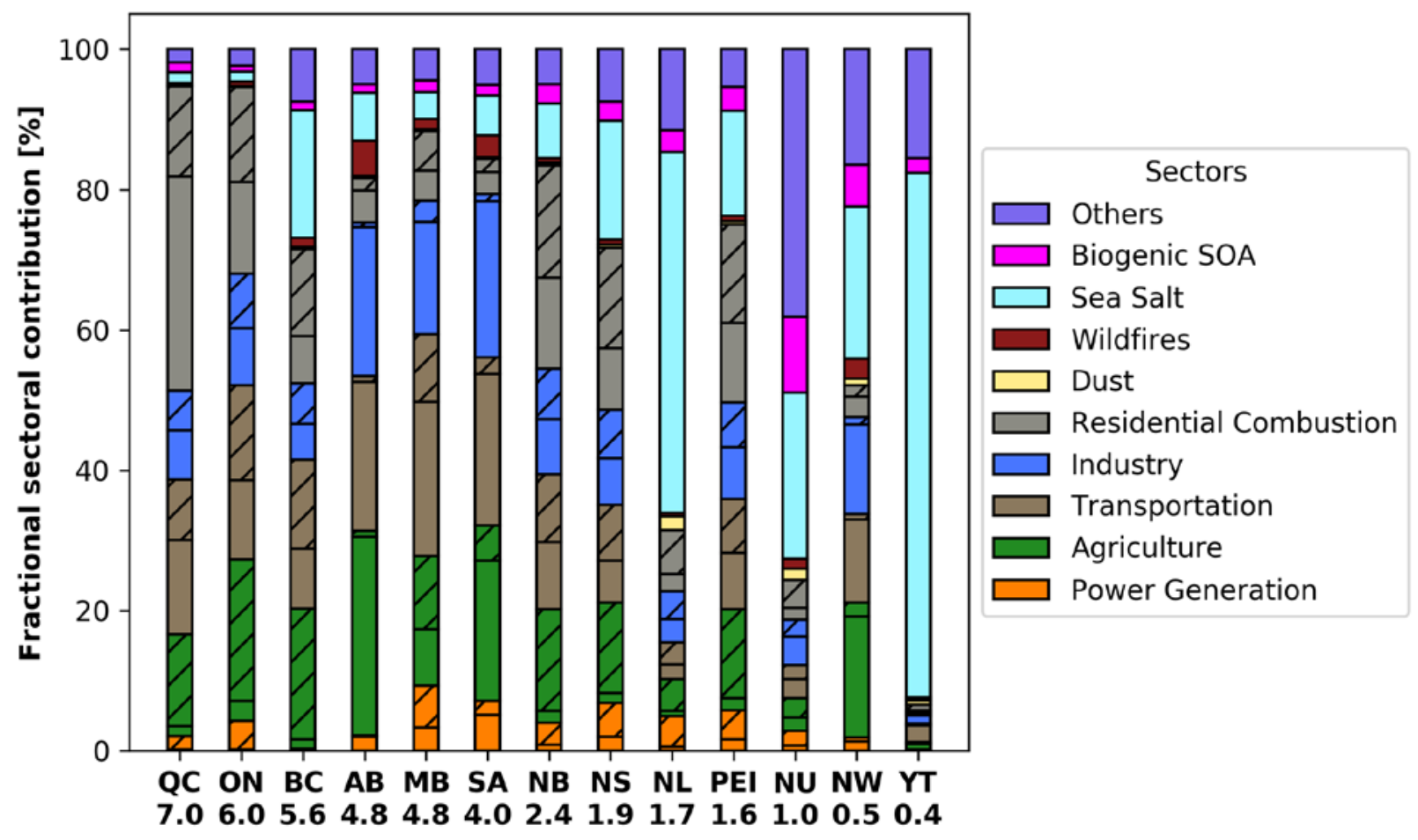

Figure S10. As in Figure S9 but averaged over winter (December, January, February). 


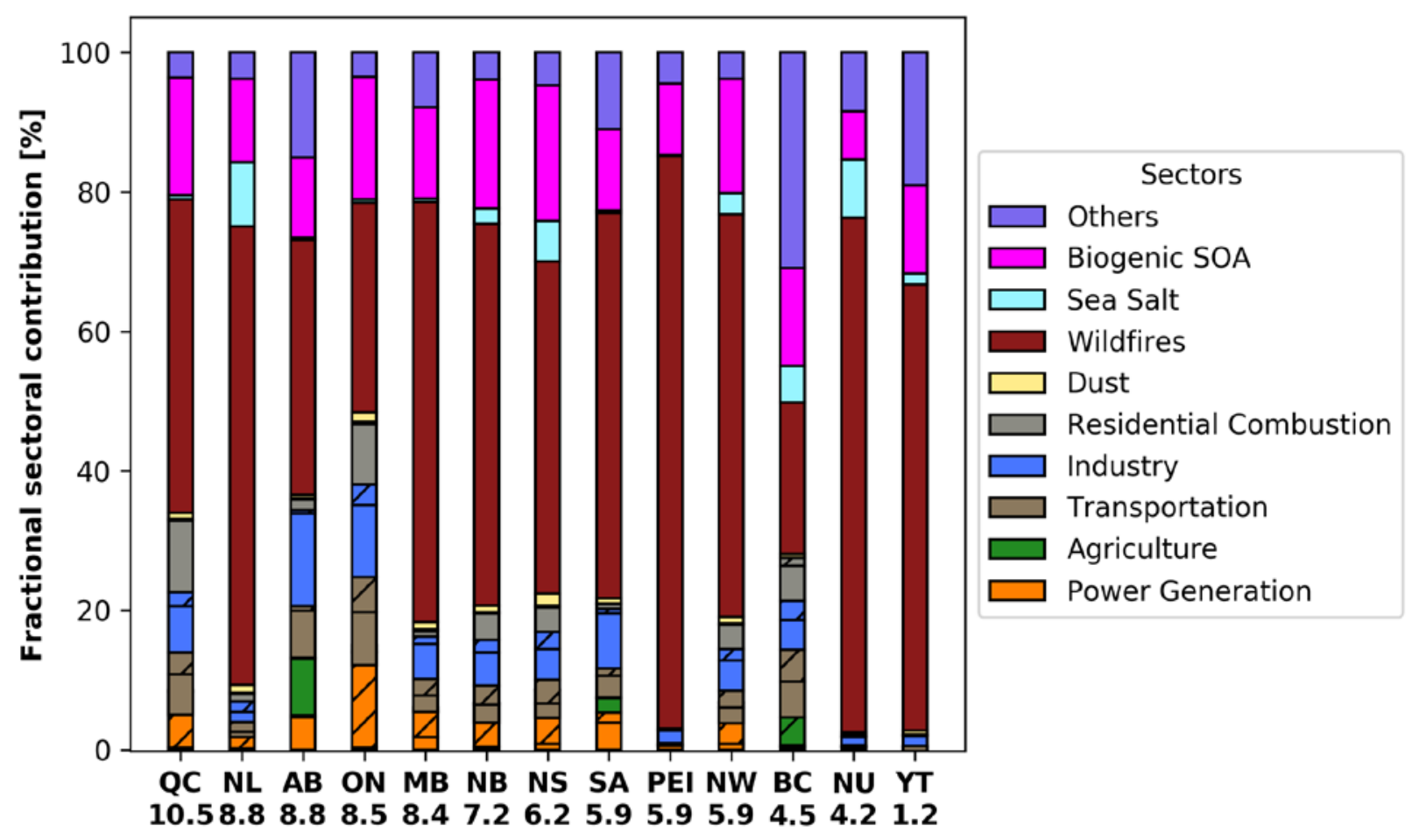

Figure S11. As in Figure S9 but averaged over summer (June, July, August).

179 
(a)

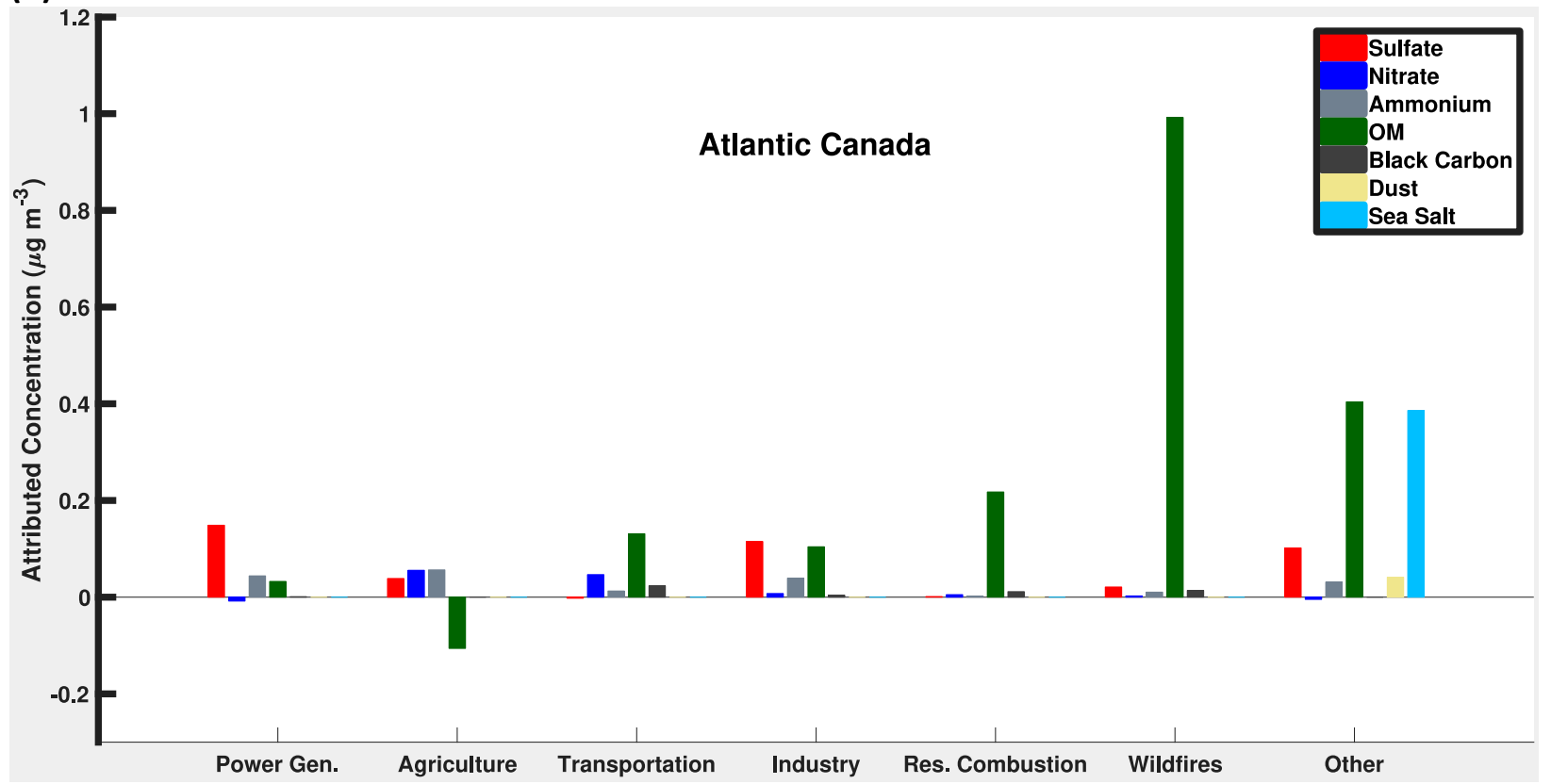

(b)

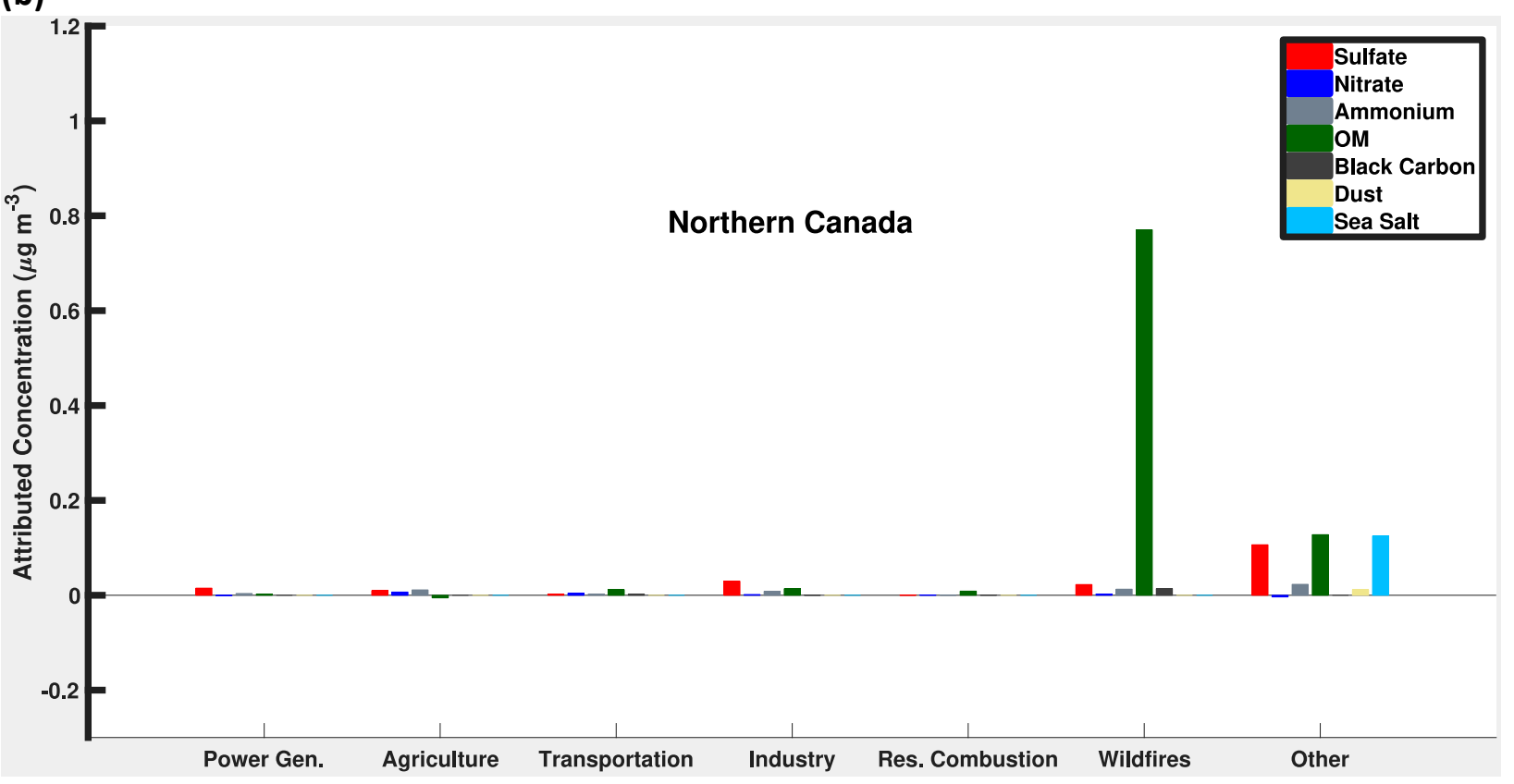


(c)

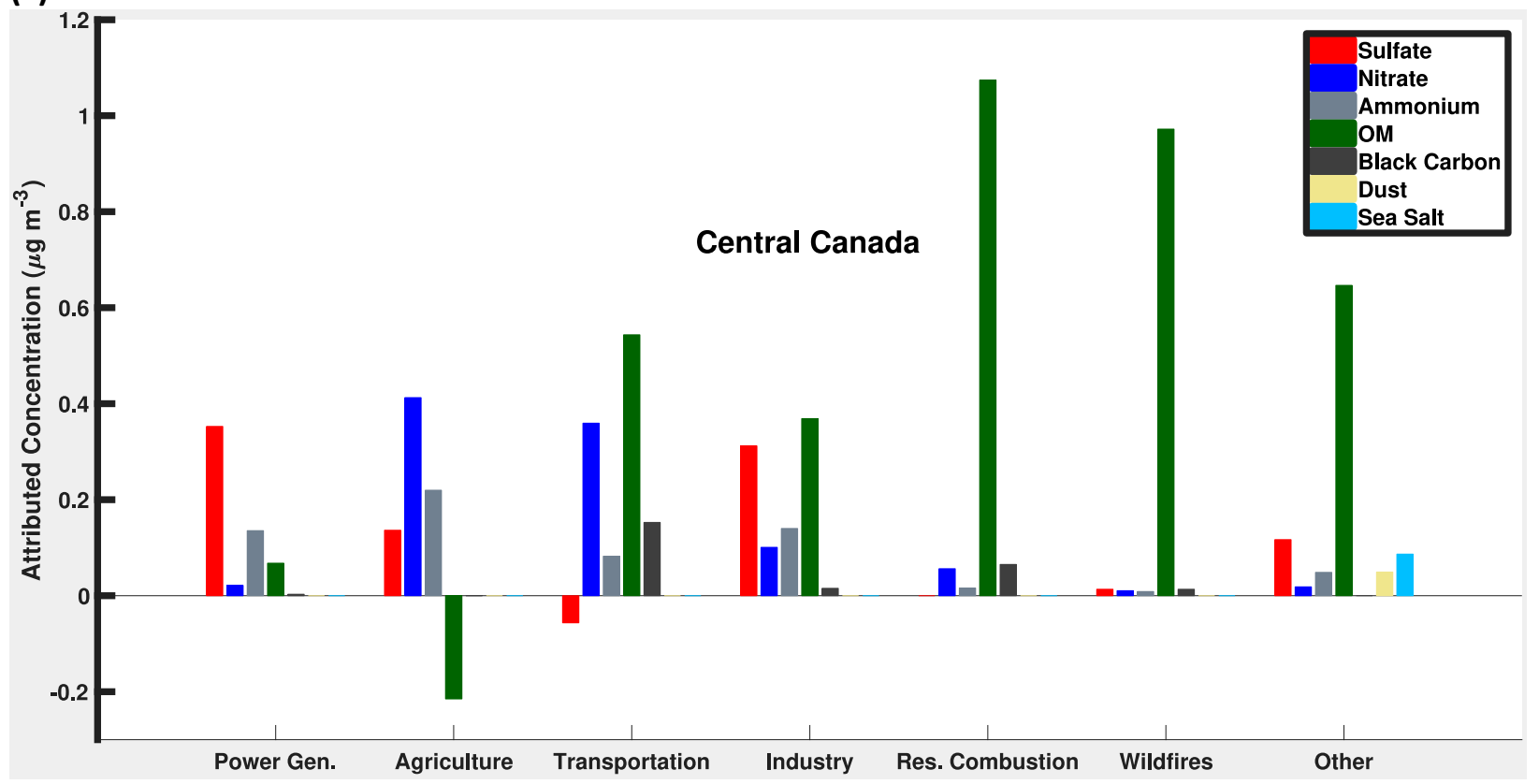

(d)

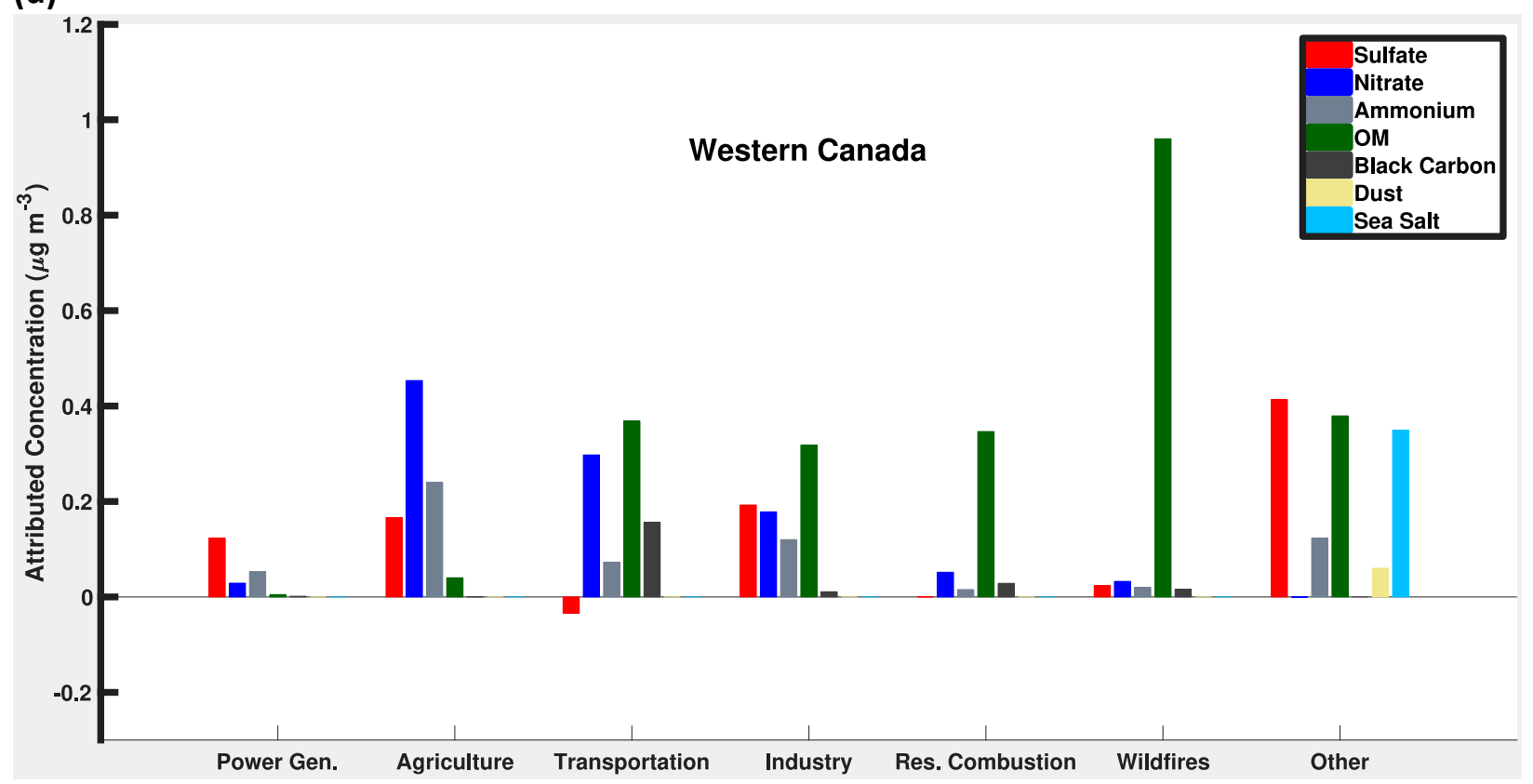

Figure S12. Population-weighted annual mean concentration of chemical components $\left(\mu \mathrm{g} \mathrm{m}^{-3}\right)$ attributed to different sectors over Atlantic, Northern, Central and Western Canada. Other includes dimethyl sulfide (DMS), volcano, biogenic secondary organic aerosol (SOA) and long-range transport (LRT) from Asia, Europe and Alaska. Figure was created using MATLAB_R2016b. 


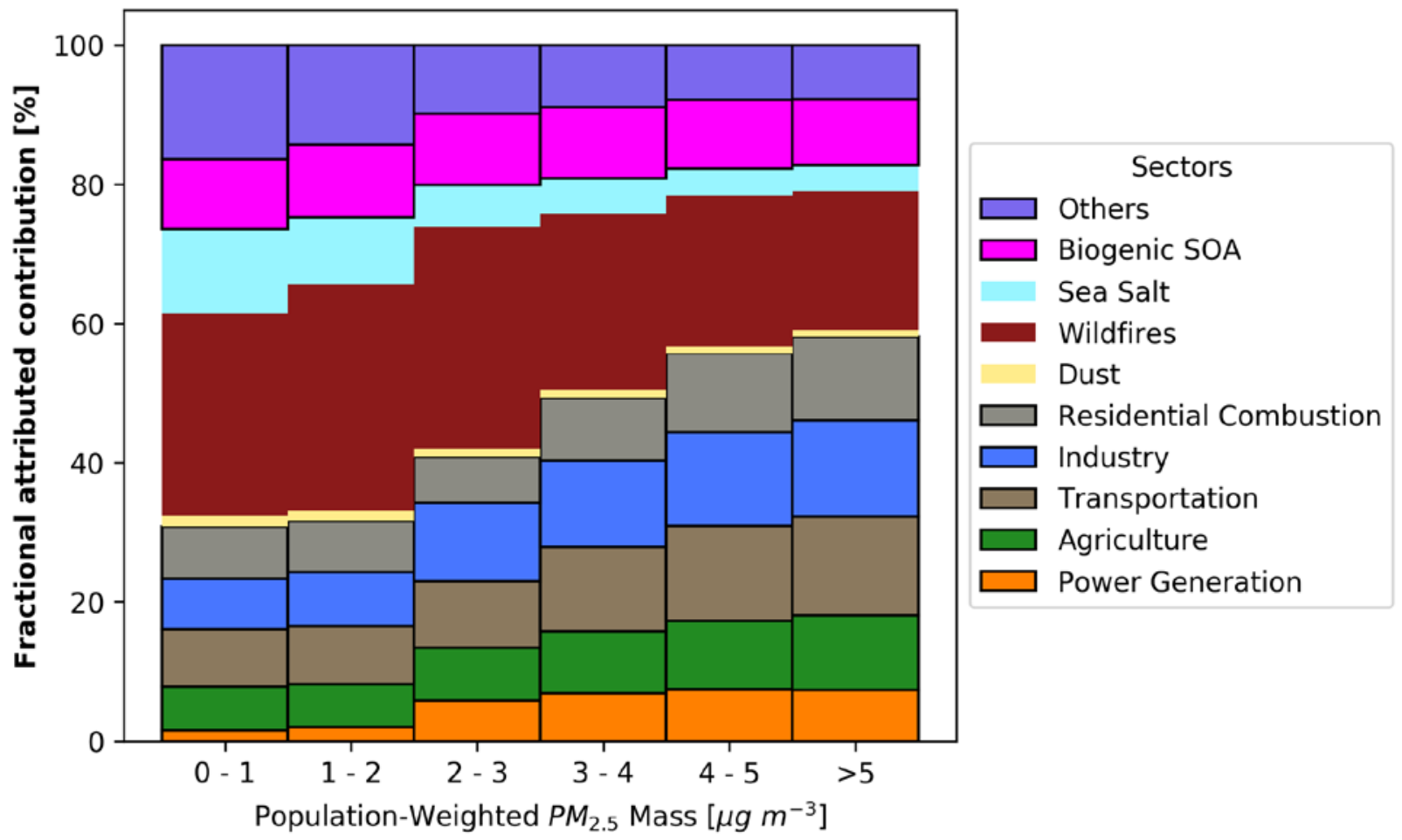

Figure S13. Population-weighted sectoral fractional contribution versus population-weighted PM2.5 mass over the United States. Stacked bar plots show percentage of each sector in different PM 2.5 levels. Other includes dimethyl sulfide (DMS), volcano, and long-range transport (LRT) from Asia, Europe and Alaska. 


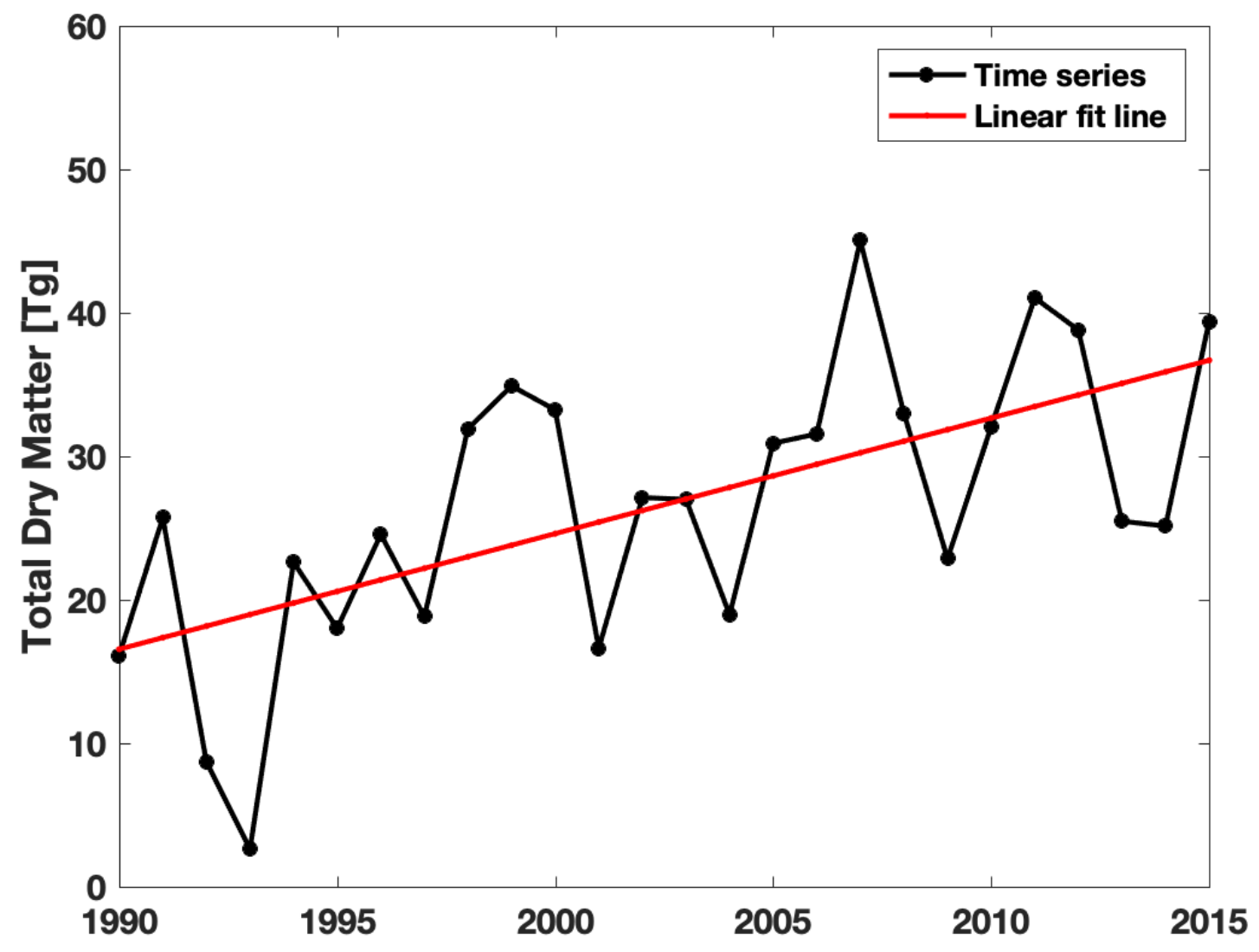

Figure S14. Annually total dry matter over Canada from wildfire emission inventories in the simulation (1990 to 1996 from ground-based North America fire emission database (cite ref here);1997 to 2015 from GFED). Figure was created using MATLAB_R2016b. 


\section{References}

256 (1) Dabek-Zlotorzynska, E.; Dann, T. F.; Kalyani Martinelango, P.; Celo, V.; Brook, J. R.; Mathieu, D.; Ding, L.; Austin, C. C. Canadian National Air Pollution Surveillance (NAPS) $\mathrm{PM}_{2.5}$ Speciation Program: Methodology and $\mathrm{PM}_{2.5}$ Chemical Composition for the Years 2003-2008. Atmospheric Environment 2011, 45 (3), 673-686. https://doi.org/10.1016/j.atmosenv.2010.10.024.

(2) Philip, S.; Martin, R. V.; Pierce, J. R.; Jimenez, J. L.; Zhang, Q.; Canagaratna, M. R.; Spracklen, D. V.; Nowlan, C. R.; Lamsal, L. N.; Cooper, M. J.; Krotkov, N. A. Spatially and Seasonally Resolved Estimate of the Ratio of Organic Mass to Organic Carbon. Atmospheric Environment 2014, 87, 34-40. https://doi.org/10.1016/j.atmosenv.2013.11.065. 